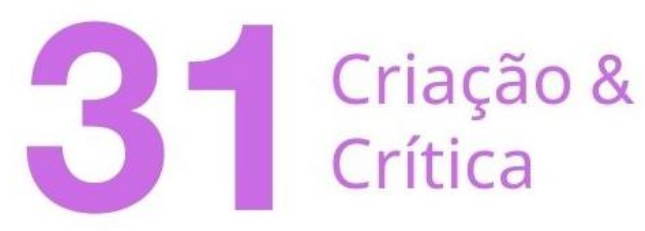

\title{
FEMINISMO NEGRO E INTERSECCIONALIDADE NA CANÇÃO “MULHER DO FIM DO MUNDO” (2015) INTERPRETADA POR ELZA SOARES
}

Francis Willams Brito da Conceição ${ }^{1}$

Resumo: Neste trabalho, objetivamos desenvolver centralmente uma análise da canção homônima ao título do disco, Mulher do Fim do Mundo (2015), interpretado por Elza Soares, tendo como aporte teórico a Teoria da Interseccionalidade - debate desenvolvido no âmbito nacional por Carla Akotirene (2018), Djamila Ribeiro (2018), Heloísa Buarque de Hollanda (2018), entre outras. Investigaremos como ocorre a relação entre gênero e raça na trajetória do eu lírico na canção "Mulher do fim do mundo" (Alice Coutinho e Romulo Fróes), interpretada por Elza Soares, trazendo breve e comparativamente outras instâncias musicais de Elza em que tais ideias são também destacadas. Para isso, partimos do pressuposto que a canção utiliza-se de um processo de metaforização da dor e solidão femininas, como acepções sentimentais diluídas no carnaval, fazendo a personagem poética deixar na avenida do carnaval, para vislumbrar uma trajetória de vida em que a arte (o cantar) se mostre como elemento possibilitador da reconfiguração de um espaço em que outras expectativas para as vozes femininas, que não a solidão e a dor, sejam possíveis na avenida, durando até o fim (SOARES, 2015, faixa 1).

PALAVRAS-CHAVE: MPB, Elza Soares, Mulher do fim do mundo, Feminismo negro, Interseccionalidade.

\section{BLACK FEMINISM AND INTERSECCIONALITY IN THE SONG “MULHER DO FIM DO MUNDO" (2015), BY ELZA SOARES}

ABSTRACT: In this work, we aim to centrally develop an analysis of the song of the same name to the album's title, Mulher do Fim do Mundo (2015), played by Elza Soares, having as the theoretical contribution the Theory of Intersectionality - debate developed at the national level by Carla Akotirene (2018), Djamila Ribeiro (2018), Heloísa Buarque de Hollanda (2018), among others. We will investigate how the relationship between gender and race occurs in the trajectory of the lyrical $i$ in the song "mulher do fim do mundo" (Alice Coutinho/ Romulo Fróes), performed by Elza Soares, bringing brief and comparatively other musical instances of Elza in which such ideas are also highlighted. For this, we start from the assumption that the song uses a process of metaphorization of female pain and loneliness, as sentimental meanings diluted in a carnival, making the poetic character leave on the avenue of carnival, to glimpse a trajectory of life in which art (singing) shows itself as an enabling element of the reconfiguration of a space in which other expectations for female voices, other than loneliness and pain, are possible on the avenue, lasts until the end (SOARES, 2015, track 1).

KEYWORDS: MPB, Elza Soares, Mulher do fim do mundo, Black feminism, Interseccionality.

Doutorando em Teoria da Literatura no Programa de Pós-graduação em Letras (PPGL) da Universidade Federal de Pernambuco (UFPE), campus Recife, com trabalho doutoral vinculado à linha de pesquisa Literatura e Estudos Culturais/ Pós-Coloniais, sobre a Colonialidade do espaço no romance histórico de Eliana Alves Cruz. Contato: franciswillams1@gmail.com. 


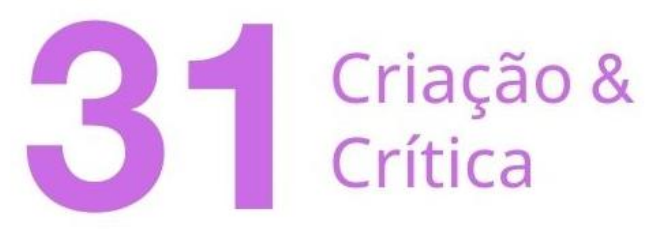

\section{Introdução}

(...) Yet what is new, and even surprising, is the contention that intersectionality is at the center of the university's intellectual and political life, that an understanding of the contemporary university requires contending with intersectionality. (Jennifer C. Nash) ${ }^{2}$

Gayatri Chakravorty Spivak (2010), em seu livro Pode o subalterno falar? afirma que não é possível falar pelo subalterno, mas que há a possibilidade de trabalharmos, de forma solidária, contra as formas de subalternização; é mais ou menos esse caminho de conscientização política que Elza Soares desenvolve em seus trabalhos com as canções, principalmente as das antologias musicais Mulher do fim do mundo (2015), Deus é mulher (2018) e, mais recentemente, Planeta Fome (2019). Usando a sua voz para "dizer o que se cala" (SOARES, 2018, Faixa 1), a cantora projeta, em sua trajetória artística, uma perspectiva interseccional, ao abordar as mulheres que, segundo Spivak (2010), são definidas como subalternas pela classe em que se inserem e por "se encontrarem em uma posição ainda mais periférica pelos problemas subjacentes às questões de gênero" (SPIVAK, 2010, p. 15).

Nesse sentido, Grada Kilomba, na abordagem do conceito de "outridade", em Memórias da plantação: episódios de racismo cotidiano (2019, p. 30), afirma que, quando a discussão sobre o racismo diz respeito à mulher negra, aponta-se, necessariamente, para um argumento de caráter duplamente periférico, pelo fato desta encontrar-se no duplo lugar das opressões de gênero e raça, sendo considerada, portanto, a "outra da outra". Diante disso, o conceito de interseccionalidade toma espaço como uma perspectiva transdisciplinar, ampliando-se e possibilitando a "instrumentalidade teórico-metodológica da inseparabilidade estrutural do racismo, capitalismo e cisheteropatriarcado", conforme enfatiza Carla Akotirene (2019, p. 19), a fim de abranger as diversas formas e manifestações das subordinações a que as mulheres negras são submetidas.

Por apresentar um caráter transdisciplinar, a teoria da interseccionalidade pode contribuir epistemologicamente com os estudos culturais, feministas, pós-coloniais e com os movimentos sociais, a exemplo das reivindicações do feminismo negro, que tem se ancorado na proposta interseccional com o intuito de demonstrar as dificuldades enfrentadas pelas mulheres negras no que diz respeito à religiosidade, classe social, origem, sexualidade, etc. Podemos caracterizar como um dos objetivos dos estudos interseccionais, entre outras acepções objetivas, a elaboração de discussões e formas de coibir a invisibilidade dos problemas de subordinação das mulheres negras, muitas vezes vistos apenas como marcados pela questão de gênero.

De acordo com Akotirene (2019), outro motivo que também impulsiona os estudos sobre interseccionalidade é o estatuto de "inalterabilidade do feminismo branco" (p. 59). Essa inalterabilidade, descrita por Akotirene, mobilizou, segundo hooks (2019, p. 89), as pensadoras feministas a exigirem que o feminismo norte-americano pautasse a realidade de

2 "E o que ainda é novo, e até mesmo surpreendente, é o argumento de que a interseccionalidade está no centro da vida política e intelectual da universidade, de que um entendimento da universidade contemporânea requer um diálogo com a interseccionalidade" (NASH, 2019, p. 12, tradução nossa). 


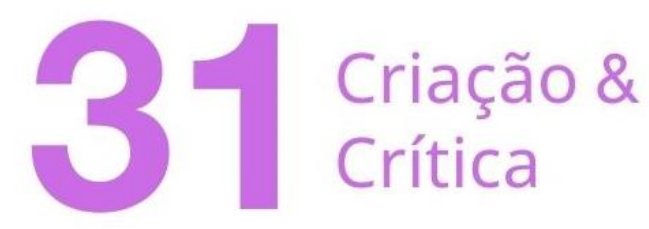

raça e racismo nas suas discussões e pautas políticas. Nesse contexto, vale mencionar que, já "em 1989, Kimberlé Crenshaw publicou em inglês o artigo Demarginalizing the Intersection of Race and sex: a Black Feminist Critique of Antidiscrimination Doctrine, Feminist Theory and Antiracist Politics, inaugurando o termo interseccionalidade" (AKOTIRENE, 2019, p.58). Portanto, a interseccionalidade surge para modificar o "jogo", os debates e os caminhos teóricos estabelecidos entre as vozes, inclusive progressistas, possibilitando novos vieses para o debate cultural e literário na contemporaneidade.

A partir dessas necessidades apontadas - de se abordar especificamente as diversas formas de subalternização das mulheres negras, como racismo, sexismo, misoginia, machismo, lesbofobia, entre outras repressões - resolvemos analisar a canção "Mulher do fim do mundo" (2015), de Alice Coutinho e Romulo Fróes, interpretada por Elza Soares, através da teoria interseccional, baseando-nos em Carla Akotirene (2019), Kimberlé Crenshaw (2002), Djamila Ribeiro (2018), Grada Kilomba (2019), entre outras. Ademais, convém ressaltar que a nossa análise, por uma questão metodológica, irá se debruçar sobre as letras (enquanto escrituras de valor estético) em detrimento a outros elementos constitutivos da canção - como arranjo, melodia, harmonia, performance, uso da voz, entre outros - que não serão contemplados neste texto.

\section{Feminismo negro e interseccionalidade: breves diálogos}

Em diversos momentos ao longo da história, as mulheres negras foram atingidas pelo silêncio/silenciamento imposto a elas pelo machismo e pelas próprias mulheres brancas (hooks, 2019), até o momento em que a discussão sobre raça e racismo fosse mais fortemente estabelecida, buscando transformar o cenário histórico de invisibilidade e legitimando as falas das mulheres negras, o que causou uma reviravolta em toda uma lógica sobre o que seriam opressão e opressor, para além da diferença sexual.

Grada Kilomba (2019, p. 41) inicia o capítulo $A$ máscara com a seguinte interrogação: "por que deve a boca do sujeito negro ser amarrada?" O silêncio pode ser caracterizado como uma forma de opressão brutal do regime escravagista, através de máscaras que, além de silenciar os/as negros/as, impedia-os/as de comer. As formas pelas quais as opressões se apresentam produzem novas maneiras de silenciar, como a invisibilidade da subordinação de cor (e não apenas de cor) enfrentada pelas mulheres negras na sociedade racista/sexista.

Todavia, as perspectivas interseccionais são responsáveis por abrir caminhos para discussões sobre racismo na pauta feminista, principalmente "no final dos anos 1970 (...)?, quando Lélia Gonzalez alertava sobre a interseccionalidade, sem o uso do termo nas suas práticas políticas, enquanto Patrícia Hill Collins escrevia trabalhos para substantivar as ações das ativistas", conforme aponta Heloísa Buarque de Hollanda (2018, p.254). Na mesma esteira de debate, as feministas Patricia Hill Collins e Sirma Bilge (2021, p. 17), ao debaterem a interseccionalidade como uma ferramenta analítica, afirmam que as ativistas negras estadunidenses se insurgiram contra o jogo que fazia das suas necessidades de educação, trabalho e acesso à saúde um simples lugar comum nas discussões sociais.

Assim, a agenda feminista passou a discutir sobre as diferentes perspectivas identitárias para a categoria mulher, especialmente através dos diálogos estabelecidos com a comunidade LGBTQIA+ (a pauta da sexualidade e da diversidade sexual), o movimento negro 


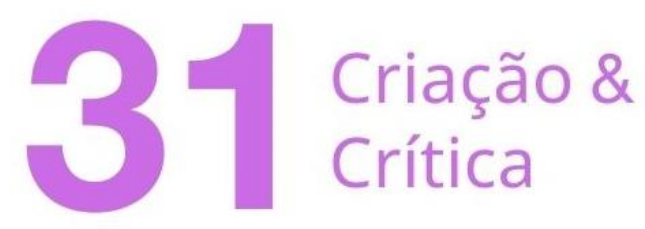

(as pautas afirmativas e políticas antirracistas) e com os movimentos sociais sindicais (a pauta sobre consciência de classe, desigualdade e pobreza). Nesse sentido, o feminismo lésbico, o transfeminismo, o feminismo marxista, o feminismo negro e outros também atraíram novos olhares para mulheres trans, negras, lésbicas e operárias, tentando inserir essas pautas nas discussões feministas, reivindicando uma desessencialização da categoria mulher, universalizada nos discursos hegemônicos. O texto abaixo evidência tal discussão:

As mulheres negras, ao criarem suas formas próprias de organização, têm mantido relação educativa com o Feminismo, enfocando as questões das diferenças entre negras e brancas. A construção desse sujeito - as mulheres negras - trouxe maior complexidade e exige 0 reconhecimento das profundas diferenças culturais nas práticas das mulheres (SOARES, 1995, p.45).

Essas discussões apontadas por Vera Soares se deram justamente pela inquietação gerada pelo slogan "enegrecendo o feminismo", marcando, conforme Sueli Carneiro, "a trajetória de mulheres negras no interior do movimento feminista brasileiro" (CARNEIRO, 2019 , p. 273). Essa relação entre as feministas negras e o feminismo acerca da invisibilidade dada as discussões sobre raça no movimento, e a necessidade de se promover a escuta de outras vozes femininas historicamente silenciadas, pode dialogar com outra composição musical: "Dentro de cada um" - de Luciano Mello e Pedro Loureiro - interpretada por Elza Soares e pertencente ao álbum Deus é mulher (2018), pois essa canção aponta para uma relação, tratada pela voz poética de maneira heterodoxa, estabelecida entre a condição feminina e as formas de silenciamento:

A mulher de dentro de cada um
não quer mais silêncio
A mulher de dentro de mim
cansou de pretexto
A mulher de dentro de casa
fugiu do seu texto
(SOARES, 2018, Faixa 10).

Desse modo, a fuga do texto do silêncio pode ser uma forma de resistir ao silêncio, não se submetendo a ele, e, como disse a escritora e feminista estadunidense Audre Lorde, "o que eu mais lamentava eram meus silêncios... E são tantos os silêncios a romper" (SOLNIT, 2017, p. 27). Ainda que o eu lírico não fale aqui de raça e nem se diga imediatamente feminino (dentro de cada um), há silêncios buscando por rompimento, no texto, via pretexto para a sonhada saída, mudança e liberdade. Para, além disso, com as discussões sobre a pauta interseccional dos feminismos, o silêncio pode aparecer como uma estratégia de resistência, como uma forma de planejamento e articulação, para dar espaço às atividades de escuta entre mulheres, permitindo a manutenção da sororidade entre as feministas, a partir dos pontos em comum entre as narrativas em disputa.

A interseccionalidade apresenta-se como um conceito utilizado e fomentado principalmente pelo feminismo negro, com o objetivo de garantir base teórica para as práticas 


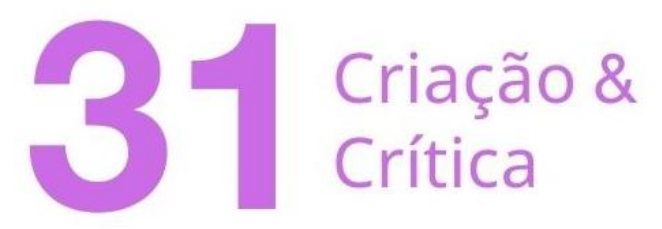

políticas das feministas e das ativistas da contemporaneidade. Desse modo, o feminismo negro, como teoria crítica social, se estabelece como uma epistemologia reflexiva, isto é, "reflete o interesse e o ponto de vista daquelas que o elaboram" (COLLINS, 2019, p. 401). Assim sendo, com o intuito de estabelecer um condicionamento epistemológico para o conceito de interseccionalidade, Kimberlé Crenshaw define-o a partir de um jogo metafórico:

A interseccionalidade é uma conceituação do problema que busca capturar as consequências estruturais e dinâmicas da interação entre dois ou mais eixos da subordinação. Ela trata especificamente da forma pela qual o racismo, o patriarcalismo, a opressão de classe e outros sistemas discriminatórios criam desigualdades básicas que estruturam as posições relativas de mulheres, raças, etnias, classes e outras. Além disso, a interseccionalidade trata da forma como ações e políticas específicas geram opressões que fluem ao longo de tais eixos, constituindo aspectos dinâmicos ou ativos do desempoderamento (CRENSHAW, 2002, p. 177).

Exemplificando essa conceituação metafórica de Crenshaw (2002), por meio de outra canção interpretada por Elza Soares - "Dura na queda", de Chico Buarque, inserida no álbum Do cóccix até o pescoço (2002) - cujo enredo mostra uma mulher, possivelmente negra. Em cena, a protagonista da composição aparece estruturalmente violentada por diversas formas de subordinação de classe e raça, perde o emprego por ser negra. Mesmo assim, ela continua a sambar no chafariz. A trama apresenta também a violência física, no trecho "já apanhou à beça". O sujeito lírico da canção é feminino, marcação social de gênero que pode ser evidenciada através das palavras morfológica e linguisticamente variáveis em gênero, como o adjetivo perdida:

\author{
Perdida \\ $\mathrm{Na}$ avenida \\ Canta seu enredo \\ Fora do carnaval \\ Perdeu a saia \\ Perdeu o emprego \\ Desfila natural
}

(SOARES, 2002, faixa 1).

Os versos "Canta seu enredo/ Fora do carnaval" pode assumir dupla produção de sentido na canção: por um lado, tal significado pode remeter ao enredo como a história de vida da mulher, sujeito lírico da canção, a qual pode estar totalmente distante e distinta da alegria e das fantasias representadas no carnaval. Essa hipótese pode ser confirmada ao longo da canção, uma vez que a mulher largou a família e tentou se suicidar. Logo, a personagem está "perdida", "perdeu o emprego", "perdeu a saia", "perdeu os anéis", mas, ainda assim, "desfila natural", sendo, portanto, a partir desse lugar que pode falar por meio da sua voz e do seu corpo. 


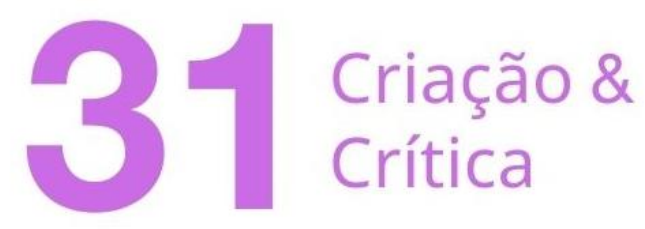

A canção pode suscitar, ainda, um sentido ligado à concepção apresentada por Djamila Ribeiro, no livro Quem tem medo do Feminismo Negro? (2018), de que a vida da mulher negra não se resume à carnavalização de seu corpo, havendo, para mulher negra, uma condição social além da avenida, ou seja, "mulher negra não é fantasia de carnaval" (2018, p. 48), tampouco sua existência está condicionada a estereótipos reguladores, como os presentes no imaginário da mulata, mãe preta e da empregada doméstica (GONZALEZ, 2020, p. 85).

Essa recorrente associação do corpo feminino negro à fetichização da mulata exportação ou à Globeleza é, de acordo com Djamila Ribeiro (2018, p.145), uma "violência escamoteada de cultura", a fim de negar o desenvolvimento de outros papéis exercidos pelas mulheres negras, deixando-as em posições subalternas e de invisibilização ou, quando visibilizadas, sempre sexualizadas. Portanto, com a perda do emprego, da saia, ela canta um enredo seu e diferente, ao final, depois de tanta "perdição" anunciada, resta ela, em seu estado natural, sabendo do que fala e do que canta, para além das perdas visíveis ao olhar externo.

Isso nos mostra o quanto a ideia de subalternização da população negra aparece como uma prática comum, sendo interceptada por múltiplas opressões de classe, gênero, origem, religiosidade, etc. Aliado a essa marcação posicional dos espaços-lugares ocupados pelas mulheres negras, como afirma Kimberlé Crenshaw (2002, p. 176), há "um problema interseccional, as dimensões raciais ou de gênero, que são parte da estrutura, teriam de ser colocadas em primeiro plano, como fatores que contribuem para a produção da subordinação". Comumente são postas como categorias estanques - gênero e raça - como se as formas de subordinação não se entrecruzassem, produzindo uma dimensão interseccional da opressão, que pode tornar óbvio todo um aparato discriminatório que coloca vários nichos em diálogo, com suas marcas de gênero, raça, classe, etc. atuando concomitantemente.

Logo, essa seção tem o objetivo de estabelecer as relações entre o feminismo negro e a teoria interseccional, uma vez que é impossível, agora, se discutir a agenda do pensamento feminista negro distante do debate sobre o cruzamento das opressões de gênero, raça e classe. A proposta interseccional tornou-se, acertadamente, a base metodológica para as ações das ativistas do feminismo negro, bem como fundamento epistemológico para as produções teóricas sobre as condições das mulheres negras, conforme afirma Carla Akotirene:

Desde então, o termo (interseccionalidade) demarca o paradigma teórico e metodológico da tradição feminista negra, promovendo intervenções políticas e letramentos jurídicos sobre os quais condições estruturais o racismo, sexismo e violências correlatas se sobrepõem, discriminam e criam encargos singulares às mulheres negras (AKOTIRENE, 2019, p. 59).

Desse modo, o intuito da relação entre o feminismo negro e a interseccionalidade é observar centralmente, a partir desse momento, a canção "Mulher do fim do mundo" (2015), de Alice Coutinho e Romulo Fróes, interpretada por Elza Soares, pelo prisma das duas teorias, pois uma mulher negra está cantando sobre a dor e a solidão, sobre a pele preta, sobre a "mulher do fim do mundo". A nosso ver, torna-se uma leitura possível, no âmbito da crítica feminista, analisar essa canção por meio da conjugação dessas teorias, sendo fundamental falar em experiências interseccionais, para citar Crenshaw (2002). 


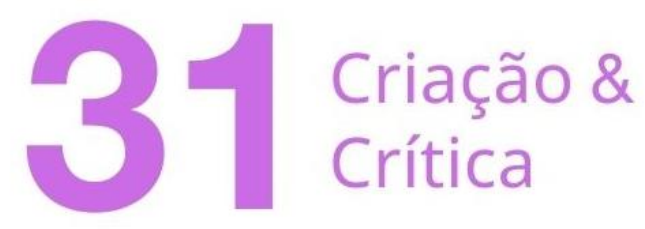

\section{"Eu não estou indo embora"3: "me deixem cantar até o fim"}

Segundo Juliana Cintia Videira (2018, p. 27), Elza Soares teve seu disco A Mulher do Fim do Mundo (2015) incluído na seleção do prêmio de melhor disco do ano por indicação da Revista New Internationalist e do New York Times, em 2016. Elza vem dando sua contribuição artística para a Música Popular Brasileira desde 1950, trazendo, em suas canções, temas considerados polêmicos pela sociedade, suscitando novos olhares acerca de algumas problemáticas como: intolerância religiosa, na canção "Exu nas escolas", uma composição de Kiko Dinucci e Edgar - que integra o álbum Deus é mulher (2018); a violência doméstica contra mulheres é criticamente tematizada na canção "Maria de Vila Matilde" - uma composição de Douglas Germano presente no mesmo disco; ou, ainda, a abordagem sobre os corpos negros em lugares subalternos e de violência física, estrutural, social e genocida, como na canção "A carne" - composição de Seu Jorge, Marcelo Yuca e Ulisses Cappellette, inserida no disco Do Cóccix até o pescoço (2002).

Elza Soares, com sua produção musical, foi intitulada pela British Broadcasting Corporation (BBC), "cantora do milênio", em 2000. Isso pode dever-se ao fato de Elza unir a arte musical às agendas sociais do país, aliás, a artista costuma deslocar, de modo pertinente, as discussões a um lugar de fala que contemple, ao máximo, o coletivo. Ela se diz marcada pelo seu entorno, compreendendo como se constitui a sociedade em que se insere, os preconceitos que circulam por esse meio.

Juliana Cintia Videira (2018) pontuou algumas diferenças entre dois discos recentes da cantora, mencionando a problematização de diversos temas sociais que remetem à condição feminina, e, dentre os argumentos, aborda o disco A Mulher do fim do mundo (2015):

Elza Soares lançou seu mais novo trabalho Deus é Mulher (2018). Se em A Mulher do Fim do Mundo as canções poetizavam as lutas das minorias e denunciavam a violência contra a mulher como com a população LGBT, em Deus é Mulher a temática feminista, como o próprio nome do álbum acena, dá o tom nas letras e na musicalidade das canções. Elza, nesses últimos trabalhos, mergulha em uma arte engajada em prol das questões que contemplam a contemporaneidade (VIDEIRA, 2018, p. 27).

Juliana Videira (2018) propõe que a temática feminista, nas antologias musicais de Elza Soares, suscita esse tom de denúncia às formas de repressão contra as mulheres negras e a população LGBT, por exemplo. Percebemos que toda essa militância da artista possui certa consonância com a luta do movimento de mulheres negras no Brasil, o qual vem caminhando paralelamente à carreira de Elza, por vezes, apoiando-se em discussões teóricas de intelectuais negras de vetores internacionais - como Angela Davis, Patricia Hill Collins, entre outras - ou baseando-se em propostas teóricas e políticas de pensadoras brasileiras, como Lélia Gonzalez, Sueli Carneiro e outras. Fica evidente que as mulheres negras

\footnotetext{
${ }^{3}$ Menção ao discurso da feminista Sojourner Truth, do original: "I am not going away/ I am going to stay here/ And stand the fire" (RIBEIRO, 2019, p. 34, 96).
} 


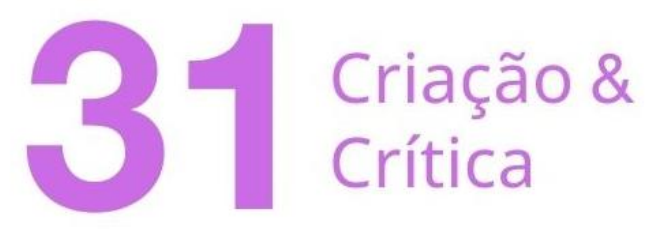

americanas, caribenhas e de outras territorialidades seguem interessadas e participando de cenários planejados e de ativismo político, em prol do empoderamento feminino.

A ideia de empoderamento feminino foi abordada por Joice Berth (2019), no seu mais recentemente livro. Neste, Berth ressalta um argumento de Angela Davis acerca da apropriação do termo pelo feminismo negro:

O conceito de Empoderamento não é novo para as mulheres afroamericanas. Por quase um século, temos nos organizado em grupos a desenvolver coletivamente as estratégias que iluminem o caminho rumo ao poder econômico e político para nós mesmas e para nossa comunidade. Ao longo da última década do século $\mathrm{XX}$, após serem repetidamente rechaçadas pelo racialmente homogêneo movimento pelos direitos das mulheres, as mulheres negras formaram seu próprio movimento associativo (BERTH, 2019, p. 96).

Nesse sentido, tal descrição sobre empoderamento feminino pavimenta as atitudes críticas e políticas a serem tomadas pelas mulheres negras ao longo do desenvolvimento do feminismo negro, fragilizando e problematizando a suposta hegemonia racial e universalidade que o feminismo branco afirma ter. A canção "Dentro de cada um", de Luciano Mello e Pedro Loureiro, interpretada por Elza Soares no álbum Deus é mulher (2018), abre a possibilidade de lastrear as ideias de uma heterogeneidade nos movimentos de mulheres:

\author{
E vai sair \\ de dentro de cada um \\ A mulher vai sair \\ E vai sair \\ de dentro de quem for \\ A mulher é você
}

(SOARES, 2018, faixa 10).

A mulher, que vai sair de dentro de cada um, não está vinculada ao silêncio; aquela de dentro de "mim", expressando as qualidades subjetivas da personagem, não se irmana ao "pretexto" de relações abusivas, em nome de "incensos". Ainda continua dizendo: a "mulher de dentro de casa/ fugiu de seu texto", apontando para as práticas domésticas como uma maneira de invisibilização das mulheres negras.

Esses diálogos são relevantes, sobretudo quando atentamos para uma parte da discografia de Elza Soares e para as notas anteriores sobre a canção selecionada. Partindo do pressuposto de que o álbum A Mulher do Fim do Mundo (2015) possui uma abordagem feminista e que discute temáticas voltadas às violências contra a população LGBTQIA+ (VIDEIRA, 2018), podemos afirmar que a letra de Alice Coutinho e Romulo Fróes apresenta uma discussão sobre a relevância social da solidão da mulher negra e da carnavalização dos corpos negros.

A canção "Mulher do Fim do Mundo" (2015), ao anunciar: "Mulher do fim do mundo/ Eu sou e vou até o fim do mundo cantar", permite uma leitura com muitas possibilidades de sentido: pode aludir ao fim, reportando-nos ao "resto dessa vida" como uma proposta 


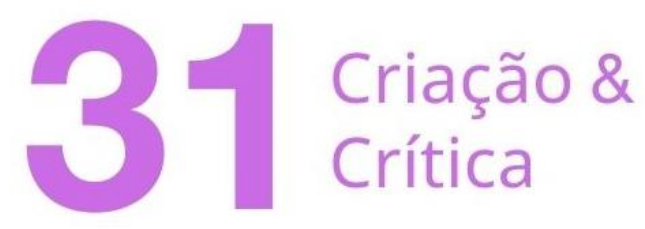

proléptica, que é "a avenida dura até o fim"; pode simbolizar as etapas conclusivas de um projeto executado pela voz que elocuciona. As reminiscências ao "fim" continuam evocando imagens outras na canção, principalmente as imagens de "mulher do fim do mundo" e "cantar até o fim". A nosso ver, esses itens mencionados sobre o "fim" (Tń remete a fim, conclusão, resultado de um percurso, consumação de uma ação) ${ }^{4}$ podem estar implicitamente relacionados com a vida e trajetória artística de Elza Soares, que, por meio de sua performance, dá vida à personagem lírica da canção.

Apesar de a canção ser toda em primeira pessoa do discurso, há uma abordagem de voz coletiva, pois quando Elza Soares traz "a pele preta" para sua interpretação, a "mulher do fim do mundo", "a solidão" e "a avenida de carnaval" estão ecoando vozes-lugares de outras muitas mulheres, que se veem representadas nesse enredo. Há o lexema "multidão", que traz a ideia de coletividade não específica e está presente na primeira estrofe:
Meu choro não é nada além de carnaval
É lágrima de samba na ponta dos pés
A multidão avança como vendaval
Me joga na avenida que não sei 'qualé'
(SOARES, 2015, faixa 1).

A estrofe acima aborda alguns itens relevantes: o primeiro verso diz: "meu choro não é nada além de carnaval", apontando diretamente para o segundo verso, em uma espécie de jogo semântico sinonímico entre "choro" e "lágrima". Mas, podemos ler de outra maneira, enfatizando que, nessa estrofe, há uma gradação literária decrescente: choro é uma semiose maior que a lágrima, sendo esta o conteúdo externo do choro, e, ao mesmo tempo, é uma ideia contrabalanceada paradoxalmente pelo samba (sinônimo de alegria para muitos) - não é qualquer lágrima, é a de "samba na ponta dos pés".

Lendo, ainda, pelo viés da gradação, podemos ressaltar: o samba é comportado na avenida (no sentido de que este cabe na avenida do desfile, na avenida da vida ou em quaisquer outras avenidas sociais) e a avenida comporta a multidão, a qual "avança como vendaval", em uma avenida, por vezes, desconhecida, em que o choro pode aparecer como elemento representativo ou performático, desaguando como uma emoção nem sempre ruim.

Essa semiose da dor, iniciada pelo choro, mediada pelo samba e finalizada pela multidão, na canção de Elza Soares, pode evocar o conceito de lugar da dor, apontado por Márcia Tiburi (2019, p. 113), que é apresentado como um lugar individual, mas que se torna coletivo, ao ser compartilhado como ambiente de escuta. Com efeito, as ideias de "lugar de fala" e "lugar de escuta" aparecem como conceitos indissociáveis, sendo, portanto imprescindíveis à compreensão do lugar do dor.

"Mulher do fim do mundo" (2015), de Alice Coutinho e Romulo Fróes, mesmo estando em primeira pessoa do discurso, realiza enunciações coletivas ${ }^{5}$, ao tratar de situações

\footnotetext{
${ }^{4}$ Conforme o sentido originalmente dado pelo Diccionario Bilingue Manual Griego Clásico-Español. 21 $1^{\text {a }}$ ed. Espanha: Anaya, 2009. Esse sentido também é o retomado por Aristóteles em sua Poética (2017), quando é proposto um fim trágico, a fim provocar o efeito catártico como paradigma para o desfecho do herói das tragédias antigas.

${ }^{5}$ Essa perspectiva se assemelha com o conceito de escrevivência, proposto por Conceição Evaristo, como, por exemplo, nas afirmações que a escritora faz em muitos de seus textos: enfatiza que "continua
} 


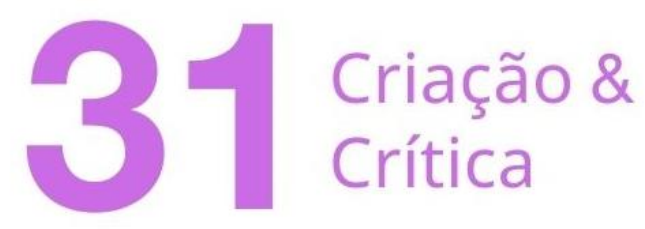

cotidianas de inúmeras mulheres negras brasileiras, fazendo que a canção interpretada por Elza Soares aponte para outras mulheres que vivem em espaços semelhantes aos da mulher do fim do mundo, retomando novamente o conceito de outridade abordado por Grada Kilomba (2019). O(A) outro(a) é a multidão que avança em uma avenida (des)conhecida, semelhante à avenida percorrida pela personagem lírica da canção, e nessa avenida, o outro e o enunciador se irmanam.

Esse lugar da dor assume tom proléptico na canção de Elza Soares:

Pirata e super-homem cantam o calor

Um peixe amarelo beija minha mão

As asas de um anjo soltas pelo chão

Na chuva de confetes deixo a minha dor

(SOARES, 2015, faixa 1).

Nessa estrofe, vale ressaltar algumas imagens de teor apocalíptico, que, por sua vez, também retomam a discussão acerca do fim: "as asas de um anjo soltas pelo chão" pode remeter a uma relação da letra com a literatura apocalíptica, perfazendo uma linha de sentido metalinguístico, que é a ideia da mulher do fim do mundo. Ainda podemos pensar, eventualmente, nesses elementos como composições de fantasias alheias, largadas pela avenida aos pedaços - asas, peixes, piratas, e ali, entre esses confetes, o eu lírico também deixa sua dor, como um resíduo da festa, da representação, da performance.

Enquanto a mulher do fim do mundo - presente no poema "Metade pássaro", de Murilo Mendes (1995) - é apresentada, poeticamente, como a quer "dar de beber as estátuas", a interpretada por Elza Soares quer cantar até o fim ${ }^{6}$. Nesse contexto, podemos afirmar que há um diálogo intertextual entre a canção de Elza Soares e o poema de Murilo Mendes. Este apresenta a mulher do fim do mundo em um tom erótico, ao iniciar pelo título do poema "metade pássaro"; já em Elza, essa mulher urge como a que resiste, como a que está em pé, mesmo quando subalternizada na avenida, como aquela que deixa a solidão e joga sua voz na sociedade e sai mais forte, por entre fantasias estraçalhadas.

Por fim, temos a última estrofe da canção:

Na avenida deixei lá

A pele preta e a minha voz

$\mathrm{Na}$ avenida deixei lá

A minha fala, minha opinião

A minha casa, minha solidão

Joguei do alto do terceiro andar

Quebrei a cara e me livrei do

Resto

no premeditado ato de traçar uma escrevivência" (EVARISTO, 2017, p. 13-14), de escrever sobre uma experiência, frequentemente semelhante, vivenciada por sujeitos femininos negros.

${ }^{6}$ Elza Soares, comentando o disco A Mulher do Fim do Mundo (2015), disse: "Eu acho que a mulher do fim do mundo é aquela que busca, é aquela que grita, que reivindica, que sempre fica de pé. No fim, eu sou essa mulher". Disponível em: https://vermelho.org.br/2015/11/18/elza-soares-temos-queacabar-com-esse-racismo-que-quase-ninguem-ve/. Acessado em: 08 Abr. 2020. 


\section{Criação \&
Crítica}

Dessa

Vida,

$\mathrm{Na}$ avenida,

Dura

Até

O fim

(SOARES, 2015, faixa 1).

Vale ressaltar um ponto relevante na estrofe acima: "a minha fala, minha opinião/ a minha casa, minha solidão/ joguei do alto do terceiro andar" explicita uma experiência de subordinação interseccional, que é exatamente a solidão da mulher negra (podendo também, por outros olhares, prenunciar uma insubordinação: ela vai protestar). Então, surge o questionamento: onde se origina o preterimento relacional a que algumas mulheres são submetidas?

De acordo com Claudete Alves da Silva Souza (2008, p. 42) ${ }^{7}$, resulta dos seguintes fatores: da interseccionalidade das opressões machistas e racistas - pois há o preterimento por parte do parceiro, privando as mulheres negras de desfrutarem, quando elas quiserem, de "uma condição de acesso social ou de estabilidade amorosa". Também podemos pensar na palavra "dura", aqui apontando para a não maciez da travessia, mas também para o verbo durar, que resiste, que dura até o fim. Portanto, mesmo o eu lírico livrando-se de tudo, ainda assim, a vida dura até o fim, ela dura até o fim.

\section{Considerações Finais}

A nossa hipótese inicial de que a canção se utiliza do processo de metaforização da dor e da solidão da mulher negra como diluídas no carnaval, faz a protagonista do enredo "deixar na avenida" a dor, "a pele preta", "a voz" e "a solidão", a fim de vislumbrar uma perspectiva apocalíptica, futura.

Tal fato pode ser confirmado a partir das perspectivas de abordagens feministas, pois a canção apresenta artisticamente a história de vida de uma mulher negra, em um enredo de uma avenida, como forma de apontar para a realidade social de problemas como: subordinação dos corpos negros, carnavalização e fetichização da mulher negra, solidão, memória da população afro-brasileira, entre outros.

A pele preta deixada na avenida simboliza, por um lado, o afastamento da memória traumática que os processos de colonização e a colonialidade deixam e, por outro, a resistência coletiva, que se dá a partir de uma memória produtiva, a qual vigora através de interesses e visa o combate à invisibilização das mulheres negras, conforme aponta Sovik, remetendo-se à canção "A Carne" (2002), composição de Seu Jorge, Marcelo Yuca e Ulisses Cappellette, com interpretação de Elza Soares:

O antepassado da cor carrega uma memória ancestral. O corpo negro é uma herança, é algo que lembra a história do país e impulsiona a

A origem do preterimento afetivo e amoroso, que mulheres negras sofrem, está diretamente relacionada, segundo Claudete Alves (2008), à condição racial e, muitas vezes, socioeconômica delas; acontece uma espécie de violência afetiva que. 


\section{Criação \&
Crítica}

luta por justiça. "A carne" aponta para uma história invisibilizada, mal lembrada, de escravas, escravos, comerciantes que fizeram fortunas, escravos libertos sem ter para onde ir, mulheres "pegas a laço", obrigadas a casar. Essa história deixou marcas nos corpos de negros e mestiços de todas as cores, das quais genealogias e histórias de família dão conta. Se o uso do revólver para a vingança é ameaçador, é a própria história que coloca em questão a branquitude como autoridade e mando (SOVIK, 2009, p. 133).

Ressaltamos que os resultados dessa pesquisa são bibliográficos, que giram em torno dos seguintes eixos: abordar a metaforização da dor deixada na avenida de carnaval como a configuração de uma ação proléptica para os bons fins estéticos da produção artística de Elza Soares, podendo ela "cantar até o fim"; enfatizar as contribuições das perspectivas interseccionais para os feminismos negros e como essas epistemologias dão suporte ao movimento de mulheres negras no Brasil.

Assim sendo, a canção "Mulher do fim do Mundo" (2015), de Alice Coutinho e Romulo Fróes, pode contribuir para lutas feministas contemporâneas, pois evidencia coletivamente a trajetória de mulheres negras de diferentes contextos que se encontram em condições semelhantes a essa mulher do fim do mundo, e para elaboração de atividades de ensino que abordem as antologias musicais de Elza Soares enquanto grande fortuna crítica, histórica e sociopolítica da Música Popular Brasileira, pois só assim faremos com que ela cante até o fim, conforme vemos: "Mulher/ do fim do mundo/ Eu sou/ Eu vou/ Até o fim Cantar".

Por fim, enfatizamos a relevância do álbum A mulher do fim do mundo (2015), de Elza Soares, para instrumentalizar as discussões propostas neste artigo. Ademais, caracteriza-se por ser uma produção notável para a discografia da cantora, uma vez que também marca seu retorno, após um longo período de invisibilidade, aos palcos e à vida artística, sendo, portanto, um disco de transição entre a ausência de Elza no campo musical do país, devido à negação machista do mercado de gravação, e a notoriedade da cantora, inclusive para lançar os álbuns posteriores, Deus é mulher (2018) e Planeta Fome (2019), os quais fomentam discussões e problemáticas semelhantes às tratadas no disco de 2015.

\section{Referências bibliográficas}

AKOTIRENE, Carla. Interseccionalidade. São Paulo: Sueli Carneiro/Pólen, 2019.

BERTH, Joice. Empoderamento. Coordenação de Djamila Ribeiro. São Paulo: Sueli Carneiro/Pólen, 2019.

ARISTÓTELES. Poética. 2ª ed. Trad. Paulo Pinheiro. São Paulo: Editora 34, 2017.

COLLINS, Patricia Hill. Pensamento feminista negro: conhecimento, consciência e a política do empoderamento. Trad. Jamille Pinheiro Dias. São Paulo: Boitempo, 2019.

COLLINS, Patricia Hill. BILGE, Sirma. Interseccionalidade. Trad. Rane Souza. São Paulo: Boitempo, 2021. 


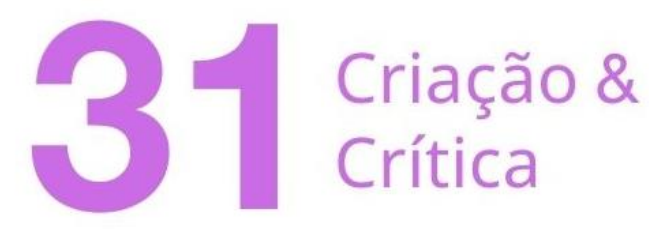

CRENSHAW, Kimberlé. Documento para o Encontro de Especialistas em Aspectos da Discriminação Racial relativos ao Gênero. Tradução de Liane Schneider. Revista Estudos Feministas. Ano 10, p. 171-188. Florianópolis: UFSC, 2002.

EVARISTO, Conceição. Becos da Memória. 3ª Ed. Rio de Janeiro: Pallas, 2017.

GONZALEZ, Lélia. Racismo e sexismo na cultura brasileira. In: Por um feminismo afro-latinoamericano. Organização de Flávia Rios e Márcia Lima. Rio de Janeiro: Zahar, 2020, p. 75-93.

Hooks, Bell. O feminismo é para todo mundo: políticas arrebatadoras. Tradução de Ana Luiza Libânio. 3ª ed. Rio de Janeiro: Rosa dos Ventos, 2019.

HOLLANDA, Heloísa Buarque de. Explosão Feminista: arte, cultura, política e universidade. $1^{\mathfrak{a} e}$ ed. São Paulo: Companhia das Letras, 2018.

KILOMBA, Grada. Memórias da Plantação: episódios e racismo cotidiano. $1^{\underline{a}}$ ed. Rio de Janeiro: Cobogó, 2019.

MENDES, M. Poesia completa e prosa. Rio de Janeiro: Nova Aguilar, 1995.

$\mathrm{NASH}$, Jennifer C. Black feminism reimagined after interseccionality. London: Duke University Press, 2019. Disponível em: https://www.dukeupress.edu/Assets/PubMaterials/978-1-47800059-4 601.pdf. Acesso em: 28 nov. 2021.

RIBEIRO, Djamila. Quem tem medo do feminismo negro? 1ª ed. São Paulo: Companhia das Letras, 2018.

RIBEIRO, Djamila. Lugar de Fala. São Paulo: Sueli Carneiro/Pólen, 2019.

SOARES, Elza. A Mulher do Fim do Mundo. São Paulo: Selo Circus, 2015.

SOARES, Elza. Deus é Mulher. Rio de Janeiro. Deckdisc/Polysom. 2018.

SOARES, Vera. Muitas faces do Feminismo no Brasil. São Paulo: USP, 1995.

SOLNIT, Rebecca. A mãe de todas as perguntas: reflexões sobre os novos feminismos. São Paulo: Companhia das Letras, 2017.

SOUZA, Claudete Alves da Silva. A Solidão da Mulher Negra: sua subjetividade e seu preterimento pelo homem negro na cidade de São Paulo. 2008. 174f. Mestrado (Dissertação) - Programa de Pós-graduação em Antropologia da PUC/SP, São Paulo, 2008.

SOVIK, Liv. Aqui ninguém é branco. Rio de Janeiro: Aeroplano, 2009.

SPIVAK, Gayatri Chakravorty. Pode o Subalterno falar? Tradução de Sandra Regina Goulart Almeida, Marcos Pereira Feitosa e André Pereira Feitosa. Belo Horizonte: Editora UFMG, 2010.

TIBURI, Marcia. Feminismo em Comum: para todas, todes e todos. 9a ed. Rio de Janeiro: Rosa dos Tempos, 2019. 


\section{Criaçăo \&}

VIDEIRA, Juliana Cintia. Elza Soares na Escola: Gênero e Relações Étnico-raciais na Música Popular Brasileira e no Ensino de História. 2018. 171f. Mestrado (Dissertação) - Instituto de Filosofia e Ciências Humanas da UNICAMP, Campinas/SP, 2018.

Recebido em: 15/07/2021

Aceito em: 30/11/2021

Referência eletrônica: CONCEIÇÃO, Francis Willams Brito da. Feminismo negro e interseccionalidade na canção "Mulher do fim do mundo" (2015) interpretada por Elza Soares. Criação \& Crítica, n. 31, p., dez. 2021. Disponível em: <http://revistas.usp.br/criacaoecritica>. Acesso em: dd mmm. aaaa. 